
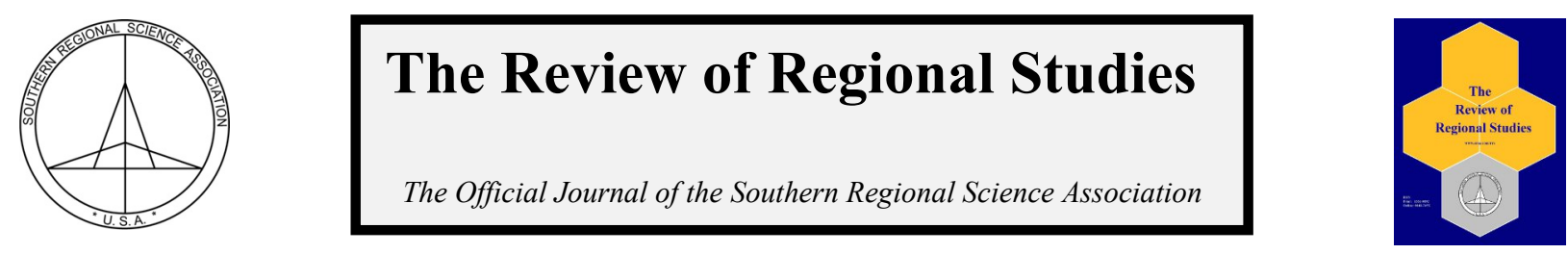

2014 SRSA Fellows Address: San Antonio, Texas March 28 $8^{\text {th }}, 2014^{*}$ $53^{\text {rd }}$ Annual Meetings of the Southern Regional Science Association

\title{
Assessing Regional Quality of Life: A Call for Action in Regional Science
}

\author{
Dan S. Rickman
}

Department of Economics, Oklahoma State University, USA

\begin{abstract}
Intellectual appeal and simplicity of use has led to the widespread application of the spatial hedonic model in assessing regional quality of life. Yet, the traditional spatial hedonic approach contains numerous assumptions, which typically are untested. Violation of the assumptions in practice can lead to significantly biased estimates of regional quality of life. More sophisticated econometric approaches have been developed to reduce the biases. However, each approach typically only addresses one or two of the concerns. More promising is the use of structural models, which by design have the potential to overcome all the limitations of the spatial hedonic approach. Keywords: hedonic estimation, spatial equilibrium, quality of life
\end{abstract}

JEL Codes: Q5, R23, R31

\section{INTRODUCTION}

Regional quality of life (QOL) typically has been assessed using the Rosen-Roback spatial hedonic framework (e.g., Blomquist, Berger, and Hoehn, 1988; Gabriel, Mattey, and Washer, 2003; Albouy, 2008). Besides QOL applications in the United States, the spatial hedonic approach has been applied to assess QOL in European regions and cities (Buettner and Ebertz, 2009; Brambilla, Michelangeli, and Peluso, 2013), Russian cities (Berger, Blomquist, and Peter, 2008), and Chinese cities (Zheng, Fu, and Liu, 2009; Zheng, Kahn, and Liu, 2010, Zheng, et al., 2014). The spatial hedonic approach likewise has been used to assess the quality of regional business environments (Beeson and Eberts, 1989; Gabriel and Rosenthal, 2004; Chen and Rosenthal, 2008).

Studies generally have found QOL differences to be related to a multitude of regional differentials in both natural and man-made household amenity characteristics. Among them, Blomquist, Berger, and Hoehn (1988) found QOL for U.S. metropolitan areas to be inversely related to humidity, cooling days, heating days, wind, violent crime, and pollution, while positively related to sunshine and the teacher-pupil ratio. Similarly, for U.S. states, Gabriel,

\footnotetext{
* Professor Rickman was named a Fellow of the Southern Regional Science Association in 2013, but elected to give his Fellows Address at the 2014 meetings.

Dan Rickman is Regents Professor of Economics and holds the Oklahoma Gas and Electric Services Chair in Regional Economic Analysis at Oklahoma State University, Stillwater, OK. Email: dan.rickman@okstate.edu
}

(C) Southern Regional Science Association 2014.

ISSN 1553-0892, 0048-749X (online)

www.srsa.org/rrs 
Mattey, and Washer (2003) found positive values for sunshine and inland water, while finding negative values for pollution, heating days, cooling days, and wind. For Russia, Berger, Blomquist, and Peter (2008) found negative values for heating degree days, water pollution, and crime, and positive values for home phone lines. Sunshine, forest cover, and water areas likewise were linked to higher quality of life in German counties, while industrial emissions and crime lowered quality of life (Buettner and Ebertz, 2009). Studies also have found a willingness to pay for lower pollution in China (Zheng, Fu, and Liu, 2009; Zheng, Kahn, and Liu, 2010).

Other applications of the spatial hedonic framework include amenity-adjusting teacher salaries (Stoddard, 2005), and estimating effects related to climate change such as temperature (Maddison and Bigano, 2003; Rehdanz, 2006; Rehdanz and Maddison, 2009), flooding (Daniel, Florax, and Rietveld, 2009; Veronesi et al., 2014), water-related amenities (Larson and Perrings, 2013), wildfires (Mueller, Loomis, and Gonzalez-Caban, 2009), recreation (Bustic, Hanak, and Valletta, 2011), and coastal values (Gopalakrishnan et al., 2011). The approach has similarly been used to examine growth-amenity feedback effects (e.g., pollution, traffic congestion) (Gabriel, Mattey, and Washer, 2003; Rickman and Rickman, 2011).

In the typical spatial hedonic application, estimated reduced-form empirical equations of quality-adjusted wages and land rents are used to produce QOL estimates. Assuming spatial equilibrium, QOL estimates are obtained as the inverse of regional real wage rates, with land rents serving as either the sole or primary regional price differential. The assumptions of the spatial hedonic approach, however, may cause significant biases in estimates of the economic values of site characteristics.

Importantly, the assumption of spatial equilibrium likely only weakly holds, even for the U.S. (Partridge et al., forthcoming). The spatial equilibrium assumption is yet more questionable for developing economies such as China with its hukou system (Zheng et al., 2014). Other issues inherent in the standard spatial hedonic methodology include sorting of people based on unobservables, endogeneity of QOL attributes, and correlation of QOL attributes with housing supply elasticities.

A number of studies have attempted to address the limitations of the standard spatial hedonic approach. Some studies have employed instrumental variables estimation to account for endogeneity of amenity attributes and factor prices that may be caused by omitted common shocks (Bayer, Keohane, and Timmins, 2009; Luechinger, 2009; Gopalakrishnan et al., 2011; Zheng et al., 2014). Other studies have accounted for sorting by examining subgroups (e.g., healthcare workers in Lee, 2010). However, these approaches only partly address the limitations.

An alternative approach that potentially can overcome all the limitations of the reducedform spatial hedonic approach is structural modeling. In the structural modeling approach: sorting can be modeled; QOL enters exogenously; restrictions on labor mobility can be incorporated; and housing supply elasticity is incorporated explicitly. Structural models can be made to match empirical outcomes of key variables in calibrating the model to historical data. At a minimum, structural models can be used to examine the sensitivity of regional QOL estimates to spatial hedonic model assumptions; structural models can reveal which assumptions are critical to obtaining accurate QOL estimates. At best, structural models may produce improved QOL estimates. Therefore, I argue that much more research is needed on using structural models for assessing regional quality of life. 


\section{SPATIAL HEDONIC MODEL}

The spatial hedonic model presentation most commonly cited is that by Roback (1982), which follows from the work of Rosen (1974). In that model, there is a representative household (h) that maximizes $U_{i}\left(X_{i}, T_{i}^{h} \mid s_{i}\right)$, subject to $w_{i}=X_{i}+r_{i} T_{i}^{h}$, where $X$ is a composite traded good, $T^{h}$ denotes residential land, and $s$ represents site characteristics, including area quality-oflife (QOL) attributes, both natural (e.g., weather) and man-made (e.g., those related to urban agglomeration and congestion). Because of perfect mobility of households, each supplying a unit of labor, indirect utility is assumed equal to $\underline{V}$ across regions in continuous spatial equilibrium: $\underline{V}=V_{i}\left(w_{i}, r_{i} \mid s_{i}\right)$.

A representative firm (f) produces the composite traded good $X$, with constant returns to scale in terms of labor and land in production: $X\left(T_{i}^{f}, L_{i} \mid s_{i}\right)$, where $T^{f}$ is land used in production of the traded good, $L$ is the units of labor, and $s$ operates as a cost shifter. Perfectly mobile firms equalize indirect costs $(C)$ across locations, which is normalized to unity: $C\left(w_{i}, r_{i} \mid s_{i}\right)=1$. Nontraded goods can be added to the model (Blomquist, Berger, and Hoehn, 1988; Beeson and Eberts, 1989; Albouy, 2008), but because of the historical absence of government regional price data on non-housing non-traded goods they routinely are omitted from the analysis. Other modifications can be made such as incorporating taxes and public good provision (Gyourko and Tracy, 1991; Albouy, 2008).

Using Roy's Identity, the amenity price $\left(P_{S}^{*}\right)$ can be shown to equal the following: $P_{s}^{*}=\frac{V_{s}}{V_{w}}=T^{h} \frac{d r}{d s}-\frac{d w}{d s}$, where $d r, d w$, and $d s$ are regional land rent, wage, and amenity differentials (Roback, 1982; Beeson and Eberts, 1989). The inverse of the real wage, with land as the only regional price differential to households, reveals the value of area amenities to households. Assuming spatial equilibrium, differences in wages versus rents are interpreted to serve as compensation for differences in household attractiveness of site characteristics.

Empirically, quality-adjusted wages and land rents are required to compute the amenity prices. Land rents can be derived from estimated quality-adjusted housing costs. After substituting the quality-adjusted prices into the amenity price expression, amenity prices can then be regressed on area QOL attributes.

However, the above explicitly and implicitly contains a number of assumptions. For one, if households are not fully mobile, amenity values will not be fully compensated into wages and rents (Bayer, Keohane, and Timmins, 2009; Zheng et al., 2014). Wages will not be driven downwards (upwards) or land rents upwards (downwards) sufficiently in areas with high (low) levels of household amenities for full compensation.

Secondly, the approach assumes that all relevant quality attributes of workers have been accounted for in the reduced-form wage regression. If there is sorting of workers based on unobservable characteristics, the amenity prices estimates may be biased. For example, if workers with unobserved highly productive characteristics sort into areas with high amenities, amenity values will be understated. Wages will be higher because of the unobservable productive characteristics, incorrectly suggesting lower amenity attractiveness of the area (Zheng, Kahn, and Liu, 2010).

Thirdly, QOL is assumed exogenous. Yet, there may be unobserved shocks that are common to both factor prices and endogenous amenities (Bayer, Keohane, and Timmins, 2009), 
causing estimated QOL estimates to be biased. Many QOL amenity attributes likely vary with the level of economic activity, e.g., pollution, crime, commuting times.

Fourthly, the above approach implicitly assumes a geographically uniform housing supply elasticity. Yet, differences in housing supply elasticities across areas have been welldocumented (Glaeser, Gyourko, and Saiz, 2008). Biased amenity price estimates result if housing supply elasticities are correlated with household-amenity attributes, (Krupka and Donaldson, 2013). For example, if amenity attributes are negatively related to the elasticity of housing supply, such as from coastal location with mountainous surrounding terrain (Gyourko, Mayer, and Sinai, 2013), amenity prices would be overstated.

\section{EMPIRICAL EVIDENCE ON THE SPATIAL EQUILIBRIUM ASSUMPTION}

Partridge et al. (forthcoming) reviewed the evidence on whether spatial equilibrium holds. They surveyed various relevant strains of the literature, ranging from subjective survey evidence on household utility to sophisticated time-series studies of regional labor market outcomes. Overall, they concluded that the vast majority of the evidence, even for the United States, suggests that spatial equilibrium at best only weakly holds.

Firstly, they reviewed the survey evidence on utility equalization across the United States. Using the General Social Survey, Glaeser and Gottlieb (2008) found that across U.S. metropolitan areas, reported happiness was unrelated to income per capita, though there were large differences in reported happiness across areas; this supports the weak form of spatial equilibrium, but not the strong form. Using self-reported responses from surveys conducted by the U.S. Center for Disease Control as part of the Behavioral Risk Factor Surveillance System, Oswald and $\mathrm{Wu}$ (2011) did not find any significant correlation between self-reported lifesatisfaction and GDP per capita, which is supportive of the weak form of spatial equilibrium. The strong form was rejected because significant differences existed across the states.

Secondly, Partridge et al. (forthcoming) reviewed the econometric evidence on utility equalization in the United States. Among the studies, based on the residuals of hedonic estimation, Clark et al. (2003) found that there was net migration towards areas where there is estimated over-compensation and away from areas where there is under-compensation. This weakly supports spatial equilibrium, though the strong form is rejected by the existence of over/under compensation. Bayer, Keohane, and Timmins (2009) found that environmental amenities were not fully capitalized into factor prices because of labor mobility costs: household ties to the area and home ownership led hedonic analysis to undervalue environmental amenities. In a study not examined by Partridge et al. (forthcoming), Luechinger (2009) found that $\mathrm{SO}_{2}$ emissions in Germany were far from fully compensated, where mobility costs were suggested as a primary reason. In a migration study of U.S. states, Greenwood et al. (1991) also found that the assumption of spatial equilibrium caused understatement of the equilibrium values of compensating differentials.

Because spatial equilibrium implies that real wages are equalized across regions, controlling for amenities, another way to assess spatial equilibrium is to test whether the wageprice elasticity equals unity. A value of unity suggests that (controlling for amenity differences) real wages are equalized across regions, which is consistent with perfect regional labor mobility. The early literature reached varying conclusions (Roback, 1988; DuMond, Hirsch, and Macpherson, 1999). More recently, Winters (2009) found that using instrumental variables 
estimation and housing rents rather than house prices, a wage-price elasticity of unity cannot be rejected, supporting the strong form of spatial equilibrium.

Partridge et al. (forthcoming) also reviewed the evidence obtained from the application of partial adjustment models. Partial adjustment models test the speed of re-equilibration of the regional economy to exogenous shocks. Their review of econometrically estimated partial adjustment models suggested that labor markets work to reduce the differentials over periods of several years to decades, only weakly supporting the spatial equilibrium hypothesis. They also examined the time-series evidence, including that obtained from application of the newer generation of time-series techniques. Generally, they reported evidence of unit roots in regional labor market outcomes such as the unemployment rate, indicating permanent effects in regional labor market outcomes following exogenous shocks and an absence of spatial equilibrium. Where unit roots were rejected, studies typically reported high persistence in regional labor market differentials in response to exogenous shocks.

\section{ECONOMETRIC APPROACHES TO ADDRESSING VIOLATION OF SPATIAL HEDONIC ASSUMPTIONS}

One alternative to the traditional spatial hedonic approach is to directly model the location decisions of households and indirectly estimate the indirect utility functions based on their location choices (Timmins, 2007; Bayer, Keohane, and Timmins, 2009). The approach relaxes the representative agent assumption, allowing for idiosyncratic tastes related to education and place of birth, which controls for sorting based on these characteristics. In addition, imperfect mobility is allowed by incorporating moving costs into the location decision, which facilitates estimating the full values of household amenities. Finally, the approach does not rely on marginal relationships, in contrast to the traditional spatial hedonic approach, which may be particularly applicable in developing countries that often possess non-marginal differences in quality of life (Timmins, 2007).

The Bayer, Keohane, and Timmins (2009) study also addressed the issue of endogeneity of pollution, which arises if local air quality is correlated with unobserved economic factors that also influence factor prices. The study used pollution that blows in with the winds from distant sources as an instrument for local pollution. Use of instrumental variables more than doubled the marginal valuation of pollution in both the hedonic and the migration approaches. Accounting for sorting and moving costs had even more dramatic effects on the estimated value of clean air.

In a study of Chinese cities, Zheng et al. (2014) likewise used cross-border air pollution externalities as an instrument to estimate the effect of local pollution on housing prices. They found the value of clean air to be greater in richer Chinese cities. Consistent with Bayer, Keohane, and Timmins (2009), they also found clean air to be more fully capitalized into housing prices where the hukou barrier to labor migration had been phased out.

Luechinger (2009) used a natural experiment created by stricter environmental regulations and wind directions to instrument for a region's own $\mathrm{SO}_{2}$ emissions in Germany. A much larger utility value for lower emissions was found using panel instrumental variables estimation and reported life satisfaction levels, though the difference between the panel and OLS estimates was not statistically significant. Empirical examination of housing rent differences and $\mathrm{SO}_{2}$ emissions produced an OLS estimate that was negative and statistically significant and a statistically insignificant instrumental variables estimate. 
Another study addressing amenity attribute endogeneity is Gopalakrishnan et al. (2011) in their valuation of ocean beach width. The study used physical variation in the coast to instrument for beach width, finding IV estimates nearly five times larger than OLS estimates. The IV estimates were then used to estimate the dynamic benefits of beach nourishment in a structural model.

In an attempt to address sorting of households into urban areas, Lee (2010) examined a subgroup of households, namely healthcare workers. Subgroups were assumed not to affect overall wages or housing costs, avoiding direct endogeneity. Lee found that doctors from better medical schools, as measured by the average MCAT score, located in larger urban areas, which was argued to derive from greater demand for urban amenities. If such an attribute was unmeasured, the spatial hedonic approach would imply that larger urban areas were unattractive to healthcare workers. The approach of Lee (2010) could be used to examine potential sorting on other amenity attributes such as pollution and natural amenities.

Partridge and Rickman (2003, 2006, 2009) constructed regional structural vector autoregression (SVAR) models, which were then used to estimate shocks to quality of life (QOL) and the subsequent dynamic responses, while allowing for imperfect short-run and longrun regional labor market adjustments. Rather than cross-sectional assumptions on real wage differences, identification of QOL effects in the SVARs was achieved through long-run restrictions on impulse response functions. The approach also allowed for estimation of the contribution of QOL shocks to employment, population, and wage growth in SVAR variance decomposition analysis.

Although the above studies addressed some of the limitations of the spatial hedonic approach, no single study addressed all the limitations together. All the studies ignored potential differences in housing supply elasticities. This suggests the need for structural models that can address all limitations simultaneously by design.

\section{STRUCTURAL MODELS TO ADDRESS VIOLATION OF SPATIAL HEDONIC ASSUMPTIONS}

Following their uses in macroeconomics, structural models are increasingly used for regional and urban analysis (Rickman, 2010). Advantages of structural models for evaluating regional QOL include the ability to exogenously shock amenity attractiveness, controlling for and/or simulating the effect of sorting of higher ability workers, varying labor mobility and/or the elasticity of housing supply, and varying preferences for amenities. Although it is well known that predictions of structural models are conditioned on the specification of the model, the assumptions of structural models are explicit, rather than implicit, as in reduced-form hedonic estimation, and increasingly structural models are empirically based or validated.

Rappaport (2009) constructed a simple general equilibrium model characterized by broad-based technological progress in traded good production (raising wages) that was able to explain much of the observed faster growth of U.S. high-amenity metro areas. Akin to computable general equilibrium models (Partridge and Rickman, 1998; 2010), Rappaport's model contains specific functional forms for household and firm behavior and was numerically simulated. He calculated a series of static equilibria to capture the growth dimension to amenity consumption. Use of the same framework in his previous work with a static model suggested that an observed 20 -fold population density difference between the second most dense and least 
dense U.S. metropolitan areas can be supported by a difference in consumption amenities valued at $30 \%$ of average consumption, a value supported by spatial hedonic studies (Rappaport, 2008).

In Rappaport (2009), there was gradual rising productivity everywhere and complementarity between goods and amenity consumption. There is a city economy with a higher amenity level and a national benchmark economy. Preferences are homothetic, but amenities are not a luxury good. Increased demand for amenities led to in-migration, putting significantly upward pressure on land prices, and moderate pressure on housing prices; housing expenditures only rose slightly because of a relative decline in consumption of housing. The importance of various elasticities in the growth predictions were examined, where Rappaport found that the results generally were robust, except to the elasticity of substitution of amenity consumption.

Yoon (2014) constructed a multi-sector dynamic spatial equilibrium model with overlapping generations of individuals to examine the decline of the U.S. Rustbelt. The model is more truly dynamic than Rappaport's (2009) in that people's expectations about future wages, rents, and mobility costs, are explicitly modeled, in which choices are age-specific. There are two regions in the model, the Rust Belt and the remainder of the U.S. Production is categorized as manufacturing, services, or housing. Labor mobility costs were empirically estimated, and were found to be higher for less-educated individuals.

Yoon introduced shocks to preferences and to technology and simulated the responses over time, finding that the model fairly accurately predicted the declining Rustbelt shares of output, employment and population over time. Predictions of Rustbelt sectoral hourly wages and the composition of the workforce and population also fit actual outcomes well. Yoon found that 50 percent of the decline in the U.S. Rustbelt production share was attributable to the reduction in its location-specific advantage in the goods-producing sector (the most important factor), followed by increasing importance of services and then the rise of the college educated share of the labor force. Mobility costs were found to widen welfare effects between individuals. He also examined the welfare effects of alternative place-based policies.

Desmet and Rossi-Hansberg (2013) constructed a multi-city model with monocentric cities to examine characteristics that lead to city size differentials for both the United States and China. The characteristics were classified into three categories: efficiency, amenities, and excessive frictions. Efficiency relates to total productivity in production, while amenities relates to the attractiveness of the city to households. Excessive frictions are those related to congestion or a less efficient government that limit city size.

The authors used aggregate data (2005-2008 for the U.S. and 2005 for China) and implications of urban theory to calibrate parameters of the model. Amenities were calculated as residuals to produce the city sizes; the authors externally verified the estimated amenity attractiveness of cities using measures of natural amenities and urban attributes. They compared estimates of efficiency to measures of wages and productivity, while also comparing their estimates of excessive frictions to common characteristics believed to be limiting city size. The authors found that highly efficient cities have larger populations, but also larger frictions. Larger median rents are found to be positively associated with household amenity-attractiveness of the city.

The fully calibrated model was then used to simulate the effects of differences in efficiency, amenities, and excessive frictions on city size and household welfare. Although large 
population effects were found for U.S. cities for each of the three categories of characteristics, small welfare gains were found for the U.S. from equalizing the characteristics across cities. For example, East Coast cities would be larger with average amenities and West Coast cities smaller, but the overall gain in welfare would be small. However, they found very large welfare effects for China. One suggested difference is that the restrictions on labor mobility in China may cause its large cities to be too small.

Behrens et al. (2011) developed a multi-city general equilibrium model with urban and trade frictions, where city sizes, productivity, and competition are all endogenous. Using data for 356 U.S. metropolitan statistical areas in 2007, they structurally estimated the model and conducted two counterfactual experiments taking into account all market and spatial equilibrium conditions. They simulated a "world" with no spatial frictions and one with frictions, separately examining trade versus urban frictions. The model was parameterized through calibration to actual data.

Although not the primary purpose of the study, amenity measures for the cities were derived from spatial equilibrium conditions, reflecting a framework where geography matters as trade and urban frictions are explicitly taken into account; thus, they derived estimates reflecting both natural and unobserved amenities, which were both correlated with city size. They found little correlation between technological possibilities and the two types of consumption amenities, consistent with empirical hedonic analysis.

Paciorek (2013) constructed a structural model of the housing investment decision, where there are owners of undeveloped land. Given exogenous demand shocks, Paciorek examined the volatility and overall levels of housing prices. A primary finding was that geographic constraints related to steepness of terrain and water proximity limit the supply of developable land and raise housing prices. These factors also were correlated with the natural amenity attractiveness of the area, where one could not estimate the separate effects of amenities and housing supply elasticity on housing prices in reduced-form hedonic estimation. The analysis provided insights into potential biases in hedonic estimation of QOL from correlation of natural amenities with the elasticity of land supply.

Although not the primary purpose of the article, Moretti (2013) used a simple general equilibrium model of two cities and stylized facts to suggest that the observed declining urban wage premium for skill in the United States is mostly related to locally skill-biased technical requirements in large cities. The higher nominal wages received are offset by a higher cost of living. This contrasts with the hypothesis that urban amenities attract college graduates, with supply as the primary economic driver. However, the stylized evidence is highly aggregated, suggesting the need for a more rigorous, disaggregated model.

\section{CONCLUSION}

The simplicity and ease of use of the spatial hedonic model has led to extensive and widely varying applications related to assessing regional quality of life. However, the simplicity and ease of use comes at a cost. The spatial hedonic approach contains numerous implicit, untested assumptions: perfect or nearly perfect labor mobility; no sorting of people based on unobservables; exogeneity of QOL attributes; and no correlation of QOL attributes with housing supply elasticities. Violations of the assumptions in practice can lead to significantly biased estimates of regional QOL.

(C) Southern Regional Science Association 2014. 
A number of studies have attempted to overcome the limitations of the traditional spatial hedonic approach. Firstly, several studies have used more sophisticated empirical designs and econometric methodology, including instrumental variables estimation and natural experiments. However, typically these only overcome one or two of the limitations. Good instruments and natural experiments also are not always available for the issues of interest. Secondly, and more promising, is that structural models have begun to be developed. Structural models can serve both as substitutes and complements to existing econometric-based approaches.

Structural models by design can address the issue of untested assumptions in traditional spatial hedonic estimation. Although the predictions of structural models are affected by assumptions related to the structure of the regional economy, structural models increasingly are empirically based or validated. Akin to the debate on the use of input-output versus computable general equilibrium models (Partridge and Rickman, 1998; 2010), at least the assumptions of structural models are explicit and can be examined for their influence on model predictions. Structural models not only can be used as substitutes to traditional spatial hedonic analysis, they also can be used in complementary fashion to critically assess the likely accuracy of traditional spatial hedonic analysis in various settings. The varied and important quality-of-life issues facing us in the future will require a multiplicity of approaches, where structural modeling should increasingly play a prominent role.

\section{REFERENCES}

Albouy, David. (2008) “Are Big Cities Really Bad Places to Live? Improving Quality-of-Life Estimates across Cities,” NBER Working Paper Series, Working Paper 14472.

Bayer, Patrick, Nathaniel O. Keohane, and Christopher Timmins. (2009) "Migration and Hedonic Valuation: The Case of Air Quality," Journal of Environmental Economics and Management, 58, 1-14.

Beeson, Patricia E. and Randall W. Eberts. (1989) "Identifying Productivity and Amenity Effects in Interurban Wage Differentials," Review of Economics and Statistics, 71, 443-452.

Behrens, Kristian, Giordano Mion, Yasusada Murata, and Jens Südekum. (2011) "Spatial Frictions," CEP Discussion Paper No. 1108, last accessed in November 2014 at http://cep.lse.ac.uk/pubs/download/dp1108.pdf

Berger, Mark C., Glenn C. Blomquist, and Klara Sabirianova Peter. (2008) "Compensating Differentials in Emerging Labor and Housing Markets: Estimates of Quality of Life in Russian Cities," Journal of Urban Economics, 63, 25-55.

Blomquist, Glenn C., Mark C. Berger, and John P. Hoehn. (1988) "New Estimates of Quality of Life in Urban Areas," American Economic Review, 78, 89-107.

Brambilla, Marco, Alessandra Michelangeli, and Eugenio Peluso. (2013) "Equity in the City: On Measuring Urban (Ine)quality of Life," Urban Studies, 50, 3205-3224.

Buettner, Thiess and Alexander Ebertz. (2009) "Quality of Life in the Regions: Results for German Counties," Annals of Regional Science, 43, 89-112.

Bustic, Van, Ellen Hanak, and Robert G.Valletta. (2011) "Climate Change and Housing Prices: Hedonic Estimates for Ski Resorts in Western North America," Land Economics, 87, 7591.

(C) Southern Regional Science Association 2014. 
Chen, Yong and Stuart S. Rosenthal. (2008) "Local Amenities and Life-Cycle Migration: Do People Move for Jobs or Fun?," Journal of Urban Economics, 64, 519-537.

Clark, David E., William E. Herrin, Thomas A. Knapp, and Nancy E. White. (2003) "Migration and Implicit Amenity Markets: Does Incomplete Compensation Matter?," Journal of Economic Geography, 3, 289-307.

Daniel, Vanessa E., Raymond J.G.M. Florax, and Piet Rietveld. (2009) "Flooding Risk and Housing Values: An Economic Assessment of Environmental Hazard," Ecological Economics, 69, 355-365.

Desmet, Klaus and Esteban Rossi-Hansberg. (2013) "Urban Accounting and Welfare," American Economic Review, 103 2296-2327.

DuMond, J. Michael, Barry T. Hirsch, and David A.Macpherson. (1999) "Wage Differentials across Labor Markets and Workers: Does Cost of Living Matter?," Economic Inquiry, 37, 77-598.

Gabriel, Stuart A., Joe P. Mattey, and William L.Washer. (2003) "Compensating Differentials and Evolution in the Quality-of-Life among U.S. States," Regional Science and Urban Economics, 33, 619-649.

Gabriel, Stuart A. and Stuart S. Rosenthal. (2004) "Quality of the Business Environment versus Quality of Life: Do Firms and Households Like the Same Cities?," Review of Economics and Statistics, 86, 438-444.

Glaeser, Edward L. and Joshua D. Gottlieb. (2008) "The Economics of Place-Making Policies," Brookings Papers on Economic Activity, 155-239.

Glaeser, Edward L., Joseph Gyourko, and Albert Saiz. (2008) "Housing Supply and Housing Bubbles," Journal of Urban Economics, 64, 198-217.

Gopalakrishnan, Sathya, Martin D. Smith, Jordan M.Slott, and A. Brad Murray. (2011) "The Value of Disappearing Beaches: A Hedonic Pricing Model with Endogenous Beach Width," Journal of Environmental Economics and Management, 61, 297-310.

Greenwood, Michael J., Gary L. Hunt, Dan S. Rickman and George I. Treyz. (1991) "Migration, Regional Equilibrium, and the Estimation of Compensating Differentials," American Economic Review, 81, 1382-1390.

Gyourko, Joseph and Joseph Tracy. (1991) "The Structure of Local Public Finance and the Quality of Life," Journal of Political Economy, 99, 774-806.

Gyourko, Joseph, Christopher Mayer and Todd Sinai. (2013) "Superstar Cities," American Economic Journal: Economic Policy, 5, 167-199.

Krupka, Douglas J. and Kwame N. Donaldson. (2013) "Wages, Rents and Heterogeneous Moving Costs," Economic Inquiry, 51, 844-864.

Larson, Elisabeth K. and Charles Perrings. (2013) "The Value of Water-Related Amenities in an Arid City: The Case of the Phoenix Metropolitan Area," Landscape and Urban Planning, 109, 45-55.

Lee, Sanghoon. (2010) “Ability Sorting and Consumer City," Journal of Urban Economics, 68, $20-33$.

(C) Southern Regional Science Association 2014. 
Luechinger, Simon. (2009) "Valuing Air Quality using the Life Satisfaction Approach," Economic Journal, 119, 482-515.

Maddison, David J. and Andrea Bigano. (2003) "The Amenity Value of the Italian Climate," Journal of Environmental Economics and Management, 45, 319-332.

Moretti, Enrico. (2013) "Real Wage Inequality," American Economic Journal: Applied Economics, 5, 65-103.

Mueller, Julie, John Loomis, and Armondo Gonzalez-Caban. 2009 "Do Repeated Wildfires Change Homebuyers' Demand for Homes in High-Risk Areas? A Hedonic Analysis of the Short and Long-Term Effects of Repeated Wildfires on House Prices in Southern California," Journal of Real Estate Finance and Economics, 38, 155-172.

Oswald, Andrew J. and Stephen Wu. (2011) "Well-Being across America," The Review of Economics and Statistics, 93, 1118-1134.

Paciorek, Andrew. (2013) "Supply Constraints and Housing Market Dynamics," Journal of Urban Economics, 77, 11-26.

Partridge, Mark D. and Dan S. Rickman. (1998) "Regional Computable General Equilibrium Modeling: A Survey and Critical Appraisal," International Regional Science Review, 21, $205-248$.

. (2003) "The Waxing and Waning of Regional Economies: The Chicken-Egg Question of Jobs vs. People," Journal of Urban Economics, 53, 76-97.

. (2006) "An SVAR Model of Fluctuations in U.S. Migration Flows and State Labor Market Dynamics," Southern Economic Journal, 72, 958-980.

. (2009) "Canadian Regional Labour Market Evolutions: A Long-Run Restrictions SVAR Analysis," Applied Economics, 41, 1855-1871.

. (2010) "Computable General Equilibrium (CGE) Modelling for Regional Economic Development Analysis," Regional Studies, 44, 1311-1328.

Partridge, Mark D., Dan S. Rickman, M. Rose Olfert, and Ying Tan. (Forthcoming) "When Spatial Equilibrium Fails: Is Place-Based Policy Second Best?," Regional Studies, DOI: 10.1080/00343404.2013.837999.

Rappaport, Jordan. (2008) “Consumption Amenities and City Population Density," Regional Science and Urban Economics, 38, 533-552.

. (2009) "The Increasing Importance of Quality of Life," Journal of Economic Geography, 9, 779-804.

Rehdanz, Katrin. (2006) "Hedonic Pricing of Climate Change Impacts to Households in Great Britain," Climatic Change, 74, 413-434.

Rehdanz, Katrin and David J. Maddison. (2009) "The Amenity Value of Climate to Households in Germany," Oxford Economic Papers-New Series, 61, 150-167.

Rickman, Dan S. (2010) "Modern Macroeconomics and Regional Economic Modeling,” Journal of Regional Science, 50, 23-41.

(C) Southern Regional Science Association 2014. 
Rickman, Dan S. and Shane D. Rickman. (2011) "Population Growth in High-Amenity Nonmetropolitan Areas: What's the Prognosis?," Journal of Regional Science, 51, 863879.

Roback, Jennifer. (1982) "Wages, Rents, and the Quality of Life," Journal of Political Economy, 90, 1257-1278.

. (1988) "Wages, Rents, and Amenities: Differences among Workers and Regions," Economic Inquiry, 26, 23-41.

Rosen, Sherwin. (1974) "Hedonic Prices and Implicit Markets: Product Differentiation in Pure Competition," Journal of Political Economy, 82, 34-55.

Stoddard, Christiana. (2005) "Adjusting Teacher Salaries for the Cost of Living: The Effect on Salary Comparisons and Policy Conclusions," Economics of Education Review, 24, 32339.

Timmins, Christopher. (2007) "If You Cannot Take the Heat Get Out of Cerrado...Recovering the Equilibrium Amenity Cost of Nonmarginal Climate Change in Brazil," Journal of Regional Science, 47, 1-25.

Veronesi, Marcella, Fabienne Chawla, Max Maurer and Judit Lienert. (2014) "Climate Change and the Willingness to Pay to Reduce Ecological and Health Risks from Wastewater Flooding in Urban Centers and the Environment," Ecological Economics, 98, 1-10.

Winters, John V. (2009) "Wages and Prices: Are Workers Fully Compensated for Cost of Living Differences?," Regional Science and Urban Economics, 39, 632-643.

Yoon, Chamna. (2014) "The Decline of the Rustbelt: A Dynamic Spatial Equilibrium Analysis," last accessed in November 2014 at http://erwan.marginalq.com/HULM14s/cy.pdf.

Zheng, Siqi Q., Yuming Fu, and Hongyu Liu. (2009) "Demand for Urban Quality of Living in China: Evolution in Compensating Land-Rent and Wage-Rate Differentials," Journal of Real Estate Finance and Economics, 38, 194-213.

Zheng, Siqi Q., Matthew E. Kahn and Hongyu Liu. (2010) "Towards a System of Open Cities in China: Home Prices, FDI Flows and Air Quality in 35 Major Cities," Regional Science and Urban Economics, 40, 1-10.

Zheng, Siqi Q., Jing Cao, Matthew E. Kahn and Cong Sun. (2014) "Real Estate Valuation and Cross-Boundary Air Pollution Externalities: Evidence from Chinese Cities," Journal of Real Estate Finance and Economics, 48, 398-414. 